This is the accepted manuscript of the article, which has been published in

Children's Geographies. 2019. https://doi.org/10.1080/14733285.2019.1649361

\title{
Affective practices of everyday nationalism in an Australian preschool
}

\author{
Author: Zsuzsa Millei, Tampere University, Finland
}

Zsuzsa.Millei@,tuni.fi

https://www.tandfonline.com/eprint/JBUEUK5I5QRNDXQSV3CE/full?target=10.1080/1473

\begin{abstract}
Nationalism as an ideology seeks to assert the primacy of national community in children's thinking, beings and feelings through curricula and official school rituals. Another form of nationalism permeating the daily routines and mundane spaces of everyday life, however, often remains imperceptible to our critical gaze. This paper brings these invisible practices into sight in young children's institutional lives and uniquely focuses on their affective and emotional dimensions. To understand how these affective practices operate, it zooms in on two situations, first, in which a teacher invites young children to engage with the nation's affective and emotional dimensions, and second, where affective practices of nation are performed by children. Situations are drawn from an ethnographic study in an Australian preschool. The paper calls for more recognition of and a critical engagement with everyday nationalism and its affective practices that often go unnoticed yet seamlessly reproduce exclusive ideals of nation.
\end{abstract}

Keywords: everyday nationalism, affective practice, preschool, pedagogy of nation, childhood studies, early childhood education

\section{Introduction}

Given a certain prevailing nationalism and reluctance to receive strangers (Zembylas, 2009), the affective dimensions of everyday nationalism have aroused renewed scholarly interest (e.g. Closs Stephens 2016; Merriman and Jones 2017; Sumartojo 2017; Militz 2017). Popular forms of nationalism portray the nation as an established community to which people may relate with national pride, attachment or criticism. Distinguishing between lay and analytic use, social science and political analysis deems 'nation' a 'political fiction' (Brubaker and Cooper, 2000). 'Nation' is accomplished through discursive and institutional practices, and relations between people, bodies, material and symbolic objects and the environment (Fox and Miller-Iddriss 2008; Antonsich and Skey 2017; Millei 2019). Adding novel frames to the exploration of explicit ideological constructions and performance of 'nation' in public life and institutional practices, studies on everyday nationalism focus on daily routines and mundane spaces 
of everyday life in the accomplishment of 'nation' (see collections Antonsich and Skey 2017, Fox and Van Ginderachter 2018).

There is a growing number of study making visible and scrutinizing everyday nationalism in adult society, in very young children's institutional lives it is rarely the case (e.g. Lappalainen 2006; Millei 2019). This is not surprising since young children are seldom considered as political subjects and agents, thus attract much less attention of political scientists or geographers exploring nationalism (Skelton, 2010). While nationalism, as an ideological construction, is often flagged in policies, curricula and rituals of schools (see e.g. Beneï 2008; Mavroudi and Holt 2015; Millei and Imre 2015), everyday nationalism receives almost no attention. This might be the case since everyday nationalism often operates below the surface, hiding in taken for granted practices so it is hard to recognize and therefore research (Fox 2017; Millei 2019). Being so mundane, when it is explicated and described, it might be evaluated as adding no new insight to what is already known. Tricking this way even seasoned researchers, exploring everyday nationalism is therefore even more important. As it remains unrecognised and operates unchallenged, everyday nationalism seamlessly shape young children's views of the world, their practices and subjectivities as national subjects. In this paper, I specifically focus on the operation of the affective dimensions of everyday nationalism. I draw on two situations to make visible its operation. In the first situation, a preschool teacher invites young children to engage with the nation's affective and emotional dimensions during the regularly occurring morning circle. In the second situation, affective practices of nation are performed by children as part of free play.

The 'nation' is woven in to affective experience through representation, bodies and sensory experience, cognitive knowledge, personal memory and reflexivity, and it often becomes so taken for granted that escapes scrutiny (Sumartojo 2017; Merriman and Jones 2017). I scrutinize mundane practices to make visible how children as young as four and five years of age are invited to feel 'nation' through a range of everyday experiences, paying close attention to how feelings and affect are built, arranged and situated - by participants, bodies, material environment, discourses, sensations and their relations. I also highlight how already at a young age children possibly relate to and perform nation, yet my observations here permit no conclusions about children's meaning making or sense of belonging; I have focussed on that earlier (e.g. Millei and Imre 2015). Preschool is a good research site as education is prominent in the "nationalisation of everyday life" (Paasi 1999; 13; Beneï 2008). I use data from an ethnographic study with children aged 3-5 to summarize the different manifestations of affective performances, then zoom in on two specific events for more detailed analysis. I conclude by calling for critical engagement with these rarely scrutinised habitual practices. 


\section{Young children and affective dimensions of everyday nationalism}

Billig (1995) in his study demonstrates how belief in the existence of nation, and people's membership thereof, are continuously forged through an iterative practice in social life, making nation an ongoing project continuously reinventing itself by adjusting to changing circumstances. Nation becomes part of everyday routine and experience as it is mediated through various symbolic, institutional and social practices and discourses allowing for nation to assume different forms (Paasi 1999). In preschools and schools, a fictional nation is created by state sanctioned national ideology prevalent in school policies, curriculum, textbooks, celebrations, mandated rituals and so on seeking to shape children's self-understanding (Paasi 1999; Mavroudi and Holt 2015; Silova et al. 2014). Exploring nationalism in children's institutional settings can be focused on the practices these state machineries are engaged with; where they "are themselves shot through with the social, cultural, and political agency of a range of actors, from educational officials and inspectors to, as crucially, teachers, parents, and pupils" (Beneï 2011, 878).

This fictional and always changing nature of nation (as opposed to a set political ideology) highlights the importance of studying 'when, where or how is the nation' made a reality (Brubaker 2006) and how people relate to those constructions. Research on everyday nationalism emphasizes the constitutive, performative and affective processes and mechanisms of nation with a focus on what people do, including attention to practices, relations, materialities and environments, objects, feelings and affects (Antonsich and Skey 2017). Considering young children (even just a couple of years old), studies of nation explore how children mobilize particular symbolic representations of nation and relations between people to include and exclude in their everyday practices (e.g. Stephens 1995; Beneï 2008; 2016). In determining whom to include and exclude, children draw on culturally significant identity markers, such as skin colour (Srinivasan 2016), practices, such as punctuality (Lappalainen 2006) or lifestyle (Millei 2019) and a variety of constructs of 'nation' and 'nationality' related to language, accents, spatialities, geographic scales and so on (Scourfield et al. 2006, and special issues on nation and childhood in Global Studies of Childhood journal 2014 and 2015). In sum, these studies richly describe how children creatively valorise national constructs, symbols and identity markers to signal superiority, or act in line with, trouble, resist or subvert these (MacNaughton, 2001).

Regarding the emotional and affective dimensions of nationalism, studies can be roughly divided into four approaches: 1) affect studies; 2) historical studies using the construct of 'structures of feeling'; 3) socialisation studies; and 4) practice approach. 1) Affect studies consider affect as an intensity or extradiscursive force (Merriman and Jones 2017), thus occurring before representation and generative beyond its identification and sensations (Anderson 2009). Studies explore how national feelings and affect possess and are apprehended by bodies and circulate between them. They focus on the emergent 
capacities and feelings associated with particular times and places, such as national celebrations and stadiums (e.g. Anderson 2009, Closs Stephens 2016), national dance events (Millitz 2017), or in more mundane forms, such as while walking to work (Sumartojo 2017). Affect is also helpful in revealing how bodies in a preschool group might be affected by and affect other bodies, such as while singing a song expressing national sentiment previously unknown to children (see Millei 2019).

2) Historical studies seek answers to how actors aim to cultivate children's emotions and appropriate emotional comportment in relation to objects, ceremonials, celebrations and heroic representations of nation. Drawing on the concept of 'structures of feelings' (a hierarchy of feelings reiterated in everyday practices), they show how teachers and parents modelled and instructed children in ways to exhibit sanctioned emotions to nation and hide or resist unsanctioned ones, also illustrating children's creative resistance towards officially sanctioned emotions in their private lives (Vallgårda, Arnfred, Alexander and Olsen 2015).

3) The socialization view posits that everyone has or ought to have an identity, hence nationalism appears as an intrinsic quality of a person. The formation of 'national' feelings is often interpreted as part of socialization towards a national identity. Throssel (2015), for example, theorizes that children become emotionally attached to nation during primary socialisation. In her view, children internalize their parents' construction of social reality and externalize their positionality to that reality. Children embrace this vision of the world and their position in it. This emotional attachment affords children a sense of belonging, identity and ontological security. The issue with this type of socialisation framework is that it emphasizes sameness over time and across persons taking nation and identity in a strong sense as real. Several critiques raised an alternative view of nation, nation as always emergent and constituted from the particularities available in different situations and contexts (Paasi 1999; Brubaker and Cooper 2000).

4) The practice-theoretical approach provides a useful framework for this study, since its focus is on how affective practices emerge, relate to objects and bodies, and how they are performed, adopted, re/worked and resisted (Antonsich and Skey 2017; Wetherell 2012). Maintaining the emergent view of nation, the practice theoretical approach treats feelings and affect as dimensions of social practices connected to discourses, maintaining their relations to representation. Affective practices are social practices organised around feelings, such as mourning, celebrating, indignation, where emotion is more pronounced (Wetherell 2012). Following an affective-discursive canon at work in cultural relations, they focus on uncovering heightened expressions of everyday transactions about identity and nation (McCreanor et al. 2017). In my analysis of ethnographic data, I follow this approach and focus on affective-discursive practices in how teachers invite and children perform nation with affective practices. 


\section{Methodology}

Besides presenting some ethnographic observations in which children are invited to 'feel the nation', I analyse two situations regularly recurring in routine preschool life: 'morning circle' and 'free play'. I selected these events because national discourses, especially national tropes, symbols and objects, are performed in these; by the teacher in the 'morning cycle' and by the children during 'free play'. Affects and feelings, according to the practice theoretical approach, are located in the practices of body gestures, eye gaze, exclamations or self-talk, but also within the flow of ordinary life. They can thus be identified in the analyses of ethnographic data that recorded these nuances as part of everyday encounters, since all affective practices are taken as part of social and cultural processes. As people interact in varying ways, they reflexively negotiate their worlds and make sense of them drawing on past experiences which orientate people in interactions (Wetherell 2012). Affective practices of nation can thus be linked to social practices and understanding of bodily expressions experienced earlier in particular contexts (Antonsich and Skey 2017).

My analysis identifies affective practices as they form part of the nation's performances, how children are invited and encouraged to feel for the nation and how some children enact affective practices of nation in their own interactions. Analysing these events shows how children are drawn into these practices and emotionally charged identifications with nation. The ethnographic data for this work were produced with preschool educators and children's participation as part of an 18-month long fieldwork period in an Australian preschool 2013-2014. Observation and field notes portray everyday routine activities, some of which I also video recorded and photographed. By so doing I sought to capture materialities and children's embodied participation in social practices, including facial and body expressions and positions, touch, feelings, objects and affective relations with objects, people, places and spaces (Pink 2009). Taking an active part as a participant ethnographer, I remained reflective of my own feelings and my visceral reactions, helping me to tune in and describe affective practices and feelings (Militz 2017). As Procter (2013) explains, emotions circulate in research situations in which the researcher is also relationally emplaced and participates. Participation and reflexivity helped me to identify, explore and claim something about teachers' and children's social and affective practices. Being a participant, a migrant with Australian citizenship, also meant that children also engaged with me and reflected on my presence, accent and various positionalities in situations that resulted in my inclusion in or exclusion from participation.

The analysis below uses two situations video-recorded and then transcribed. Using videorecording helped me to repeatedly view a situation focusing and describing different aspects, such as materialities, bodily movements, facial expressions, relations of bodies and objects in space. Photos 
served similar purposes and I also used them for photo-elicitation in spontaneous discussions with the children. However these were less useful in describing how actual practices took place. Ethical consent followed the Australian and University of Newcastle protocols of ethical research involving children. After obtaining consent from families on their children's behalf and also from the preschool Management Committee and participating adults, the children gave continuous consent in that they were repeatedly asked for their agreement to participate and to the use of data. They also had a chance to review the data, which also afforded a great opportunity to elicit their views on their artworks and events recorded. Children's names were changed to protect their privacy. Consent to present and publish research material was sought from the preschool's Management Committee and the Director before each submission.

\section{Affective practices and nation in everyday preschool life}

Nation was omnipresent in the preschool, forming part of the rich experience of the everyday connected to particular material environments and reproduced through daily habits, routines and practices. Joshua arrived at preschool with the word 'Aussie' and the Southern cross temporarily 'tattooed' on his arm with a sticker, and a star sign portrayed on the Australian flag. He proudly showed it to other children beaming as others studied it more closely. Elsewhere in the preschool an educator facilitated a small group workshop teaching children about significant places and sites around Australia. After pointing its location on the map, she described each place, city and site. Paasi (1999) understands this practice as spatialising the nation, which transforms geographical locations into 'national landscapes'. The educator asked certain children if they had actually visited the place and how they spent the time there. The educator helped recall these pleasant memories relating children to these places. These social practices of spatialising and emotionally relating serve to connect national identity, territory, culture, history, language and memory (Paasi, 1999). Such activities strengthen affective and cognitive links producing temporal and spatial constellations, a kind of lay 'geographical knowledge' of nation (Edensor and Sumartojo 2018, 555). The activity concludes with a song 'Going around Australia just to have some fun'. Children and educator formed a circle, walked around the map on the floor and sang, stopping at a place chosen by the educator. At that place, also pointed out on the map, actions proposed by nominated children were performed, such as hopping or skipping. Smiles, laughs and joyful chatter accompanied these movements. Spatialization here extended to include embodied ways of learning the territory of the nation, sensing and feelings to encourage spatial belonging (Edensor and Sumartojo 2018).

On another day, Susie arrived in morning circle with a passport, a home-made paper booklet. She showed her carefully drawn photo, name and the cover of the passport with the Australian coat of arms. 
The children passed the passport round, studying the kangaroo and the emu on its cover, while the teacher explained about having a passport and what the coat of arms and Australian animals on it represent. Her erect body radiated pride and her explanation was imbued with affection for these animals and the nation emerging through her story. Her story of the passport was linked to border crossing opening up the imagination to other countries and cultural landscapes (Häkli 2015). The five-dollar note that Kyle showed around during morning circle, also served as a boundary object invoking the space of the nation using this currency. The educator passed around other banknotes quickly taken out from her purse and the conversation extended to the significant symbols, buildings, memorials etc. the notes portray. Her stories re/constructed traditions through the explanation of cultural and historical representations on the notes and at the same time these narratives and her excitement invited feelings for nation (Paasi, 1999).

The preschool has a good collection of Australian classics, stories like Auqzie Easter, portraying the Australian way of celebrating Easter, a relaxed lifestyle and the bush. The bush and bush animals also appear frequently in other books read and discussed with children during morning circles or free time. Classic books entitled Snugglepot and Cuddlepie or Blinky Bill, and newer ones like Diary of a Wombat, refer to settler and Indigenous relations represented by animals. These books mirror outdated and more currently prevailing ideologies of nation playing a crucial part in constituting a national space, narratives and identities while they are read (Paasi 1999; Silova et al. 2014).

The event that I first analyse in detail also occurred during a morning circle, when children and educators gather on a large mat, usually read a story, discuss ongoing issues often raised by the children themselves and prepare for the daily workshops and other activities. Children arrive at preschool from the local area, a small town close to a larger city in New South Wales, Australia. The region around the preschool is relatively homogenous; more than $85 \%$ of the population were born in Australia ${ }^{1}$. While there could be others, only a couple of children in this group had families self-identifying as Indigenous peoples. The preschool director shared with me her passion about reconciliation that led her to introduce a greater focus on the relationship between Aboriginal and Torres Strait Islander peoples and nonIndigenous Australians. She had established a good relationship with the local Indigenous community through Barkuma Indigenous Centre, which at the time of the fieldwork had been operational for about a decade. This commitment included the employment of Indigenous educators when possible, building relationships with families and opening up spaces to tackle prejudice, discrimination and racism. In this

\footnotetext{
${ }^{1}$ In New South Wales, $65.5 \%$ of people were Australian born, in the Cessnock area of the preschool $85.5 \%$ were Australian born, and the next largest groups being England 1.9\%, New Zealand 0.9\%, Scotland 0.4\%. In Cessnock 74.2\% of people had both parents born in Australia. http://www.censusdata.abs.gov.au/census services/getproduct/census/2016/quickstat/SED10017
} 
morning circle event the teacher read Possum Magic, a classic Australian children's book.

\section{Reading Possum Magic}

During the Easter break families usually travel or visit relatives. To connect with present activities in children's lives, the teacher selected an Australian story by Mem Fox titled Possum Magic for the morning circle time. This is a large book (approximately a meter tall and $60 \mathrm{~cm}$ wide) often used for group reading in early childhood education. The teacher turns the pictures towards the front row of eight children and four children sitting behind, and reads aloud. In the story, Grandma Poss(um) has made Hush the baby possum invisible (teacher whispering in excitement) to protect him from the snake. Because she could not be seen, she was squashed by the koala (and the teacher shows how Hush could have been squashed by following the floor line with the palm of her hand), she could slide down a kangaroo's back (teacher shows the slide with quick movement of her hand and a girl at front shouts "I wish I could slide down the kangaroo"). When he wanted to be visible again, Grandma Poss could not find the right magic in her book.

Teacher: "Oh, things are looking grim" (she says it in a quiet tone and makes a sad face, mouth dropping down and eyes fixed to the floor, body in stooped position). "How do you think Grandma Poss is feeling?" the teacher asks showing the picture in the book to the children and pointing to Grandma.

Girl (at front): "Sad".

Boy (middle): "Sad".

Teacher: "The word they use here is miserable" - the teacher explains. "Oh my goodness let's see" - as she sighs, turns the page and continues reading. "Grandma Poss felt miserable" (firm and then lowering tone of voice).

Boy (on the right): (goes up to book, points to the invisible Hush) "He is actually angry".

Teacher: "Don't worry grandma (elevated tone)" said Hush, "I don't mind (teacher nods as she turns her head displaying a sad face with corners of her mouth dropped, her eyes meeting the children's eyes)."

Grandma was thinking all night. The story goes on.

Teacher: "While eating breakfast she realised (teacher gasps with excitement): "SHE SHOUTED, IT'S SOMETHING TO DO WITH FOOD ( $2 \mathrm{sec})$ PEOPLE FOOD, NOT POSSUM FOOD”. (While reading this she lifts her fist up in the air and moves it as she was punching the air vigorously two times).

The next day the possums left the bush and set off with a bike to visit all of the places.

Teacher: "They ate Anzac biscuits in Adelaide" (teacher mumbling 'mmmm' - as it is yummi).

Girl (on left): "My mom goes to Adelaide".

As the teacher hears that, she turns excitedly to the child.

Teachers: "Where was your mom?"

Girl (on left): "She was in Adelaide" - the child responds and the teacher acknowledges the response with a nod.

Teacher: "She just came back last night" (teachers smiles and engages with the children's gazes).

Girl (at front in a low voice): "That's where I am going on my next holiday".

Teacher: "Mornay and Minties in Melbourne, Steak and Salad in Sydney, and Pumpkin Scones in Brisbane".

Boy (on the left): "My uncle Mat lives in Brisbane!" Teacher turns to the child with a smile and points to the child.

Teacher: “That's right, your Uncle Mat lives in Brisbane." (with excitement in her voice and huge smile on her face).

Boy (at front): "I want to go and bike now"- circles with his arms as the bicycle's wheels go. 
Teacher: "We are talking about the book now." (looks at the boy at front and turns to the book and continues to read).

Hush, the possum, remains invisible. But the tail of the possum appears on the next page as the teacher turns the page. A child notices immediately and shouts.

Boy (middle): "A TAIL, A TAIL, A TAIL APPEARS" - a boy shouts excitedly pointing to the tail. (The teacher ignores and reads on.)

Teacher: "They went to Darwin. And it was there in the heart of Australia (lowers the tone and stresses the words) that they have found a vegemite sandwich (waits a couple of seconds) and Grandma Poss got very excited then. What did she say? (Teacher lifts her arm in to the air and shouts) A TAIL. A TAIL (Repeats shouting in high pitched voice). She waits in silence for a few seconds. There is complete silence in the room and excitement fills the air. "Let's see where they are going next".

Girl (at front): "A tail that means a whole body will ... get.

Teacher: "close your eyes let's see what happens. Let's see where they go next." (with excited tone and she turns the page).

The story continues that "From that time onwards" once a year on Hush' birthday, Grandma Poss and Hush "ate a vegemite sandwich, a piece of pavlova, and a half of lamington, just to make sure that Hush stayed visible forever" (28).

Reading aloud during the morning circle is common in the preschool and an important part of preschool pedagogy. While reading aloud, the teacher assumes the role, voices and feelings of characters creating dramatizations, using the book as a springboard for children's literacy development and meaning making. Sipe (2008) characterizes responses to dramatizing as 'performative' arising spontaneously in classrooms while children are listening to and discussing literature. Children take multiple perspectives, understand shifting viewpoints and let their own imagination take flight (Sipe 2008). Here also, children learn through different modalities during the reading, such as particular gestures, movements and intonations, which help children to forge personal and social meanings and feelings around stories (Adomat 2010).

During the reading aloud, the teacher's body and movements are minutely choreographed and match her words, performing affective practices in line with her story-telling. She acts miserable with Grandma Poss at the beginning of the story, portrays relief and excitement when the solution to the problem is found, reacts to and elicits children's identification with the protagonists by connecting to their or their family's life events conjuring up familiarity in listeners. She demonstrates how to feel for the characters. In acting the characters she also conveys the characters' and her own feelings to the children. By establishing connections between the children's lives and the possums' journey, as Marjorie Goodwin $(2006,40)$ explains, "affect is lodged within embodied sequences of action", both in the bodies of the teacher and children, and larger fields of action, such as going to nationally relevant places, are also recruited and organised for the story both as affect and action. While reading, affective relations and social practices of nation infiltrate the performance carried by the book and enacted by the teacher. 
Mem Fox's book features Australian native animals and draws on the iconography of the bush and its harshness alluded to by the snake that Grandma Poss foils by making Hush invisible (Bradford 1995). The re-emergence of Hush from invisibility by eating 'Australian food' can be interpreted as a patriotic revisioning of 'Australia' (Bradford 1995). Food in literature is always symbolic, since the characters do not need to eat to stay alive. Food reinforces the 'obviousness' of cultural ideologies and carries socialising messages (Rose 1984). Food “acts to seduce readers; through mimesis it 'naturalizes' the lesson being taught; and, through the visceral pleasures (sometimes even jouissance) it produces, it 'sweetens' the discourse and encourages unreflexive acceptance of the morals thus delivered" (Daniel 2006 , 4). Through the affective practices performed by the teacher and the story's seductive effects on the child listeners, feelings for the emerging nation are injected into the reading space (Paasi 1999). The affective practices of being miserable, relived or excited or performing familiarity, the rapidly following affective practices and suspense serve to facilitate children's meaning making, feelings for and identification with the characters.

According to Rose (1984), children's fiction builds up an image of a child inside the book (in this case Hush) to make the child outside the book a target of its ideologies. Hush wants to know what she looks like, since she is invisible she has no sense of self, she lacks subjectivity and agency (Daniel 2006). Hush must eat properly to achieve visibility or proper subjectivity. The imaginary of Hush' transformation can be viewed as a "reference to the colonial past and to a version of Australianness heavily reliant on traditions of Empire" (Bradford 1995, 113). In children's stories, native animals hosted settler children to become Australian since the figures of distinctively Australian animals, such as the possum or kangaroo, were "enrolled ... into the constitution of Australia itself” (Franklin 2006, 138). Hush's subject position - being native, attractive, cute, appealing - aligns with being Anglo-Australian (Bradford 1995). This conflation "serves both to obscure and to appropriate notions of indigeneity" (Bradford 1995, 113). The native Australian animal lends the child reader the subjectivity of Australian without needing to engage with indigeneity, or indigenous cultures or subjectivities (Hateley 2017).

In Possum Magic, the quest is for personal identity and the child listener outside the book is meant to go through this search and subjectivation with Hush. The nation is constituted and identifications are encouraged through this story in at least three ways, through the body, food and the landscape (Paasi 1999). Quoting Palmer, Paasi (1999, 8) explains, "how we use our bodies, in the foods we consume and in our relationships with the landscape there is a continual reminder of who we are and what we believe in. This is why individuals do not forget their identity". In a close parallel between Hush and the listening children, the story invokes nation through body, food and landscape and as the teacher performs it with affective practices children are invited to identify and to feel with Hush. 
Wetherell $(2015,160)$ explains that "affective practice is a moment of recruitment, articulation or enlistment when many complicated flows across bodies, subjectivities, relations, histories and contexts entangle and intertwine together to form just this affective moment, episode or atmosphere with its particular possible classifications". Affective practices may thus differ in scale as they vitalise a subject, or a group of children, or as they are distributed in communal celebrations or in collective moods (referring to affective atmospheres). In this event affective practices move children's bodies, they draw their bodies closer to the book, the teacher and the characters, or distance them (perhaps in the case of Indigenous children). They also work by drawing in children's emotional, haptic and taste experiences, since many experienced eating the same food or the landscapes the characters and the children themselves visited. Children are thus encouraged to self-identify and feel with the characters.

However, there are also children who relate to the discursive and affective positioning differently by remaining silent or motionless. It is not surprising since the story uses highly stereotypical and colonial tropes in contrast to more recent imaginaries of the nation. As Turner (1994) explains, since the 1990s Australia has been characterized by notions of plurality and hybridity. Cultural difference is seen as constitutive of Australian national identity rather than a deviation from an Anglocentric and normative identity that Possum Magic conjures up. A boy (on the right) disagrees with the story and its interpretation and pronounces: the possum feels angry (instead of miserable). Another boy (at the front) connecting with the story differently wants to go on a bike ride, as the possums did, without identifying with the character or connecting to the story as performed by the teacher. Yet another boy goes along with the story but points to the appearance of tail too early. He perhaps wishes to show that he is paying attention and is quick thinking. Thus children engage very differently with the storyline and the affective practices and national tropes mobilized.

The material environment and objects also enter actively into the organisation of the affective display during the reading aloud. The large book itself and its illustrations play a crucial role in and accentuate the teachers' affective practices. The teacher's central and elevated position on a small chair turning towards the children who sit on the ground; the mat that keeps the children in front of the teacher; being 'contained' by another teacher sitting in the back; together create illusionary borders, orientate and control children's attention and help the production and co-ordination of the affective display. In the next situation, the material environment and objects play an even more significant role as children affectively perform a national trope.

Fishing boat and camping chairs: An Australian barbecue 
The children put camping chairs next to a life-size fishing boat during free outside play in the preschool garden. In this preschool children are allowed to bring out toys or equipment from the shed and use them freely. They have created a barbecue scene.

Four boys and a girl are sitting on the chairs holding their water bottles and gazing at the large plastic building blocks in front of them (see Figure 1). On the ground plastic fish and crabs are placed on a wire rack. The children strike a relaxed sitting pose, legs spread out wide and slouch down in their chairs. I ask while approaching: 'What is happening here?' A couple of them excitedly answer in chorus: 'We are drinking here!" The boy in the middle straightens up and crosses his legs, lifts them from the ground and moves his crossed legs up and down striking a relaxed pose. I ask: 'Whose place is this?' John answers: 'Only for boys!' The other boys look at the girl who smiles with some surprise on her face. John lifts both shoulders and relaxes his face almost as much as his jaws drop down completely. He slightly lowers his head and gazes at the ground. There is suspense. He then casually points to James with a relaxed arm gesture and pronounces affirmatively: "You can come in." In response I ask in an emphasized teenage girl style: "Can I come in?" the firm answer arrives in a matter of fact tone and deep voice: 'Girls cannot come in'. A boy leaves the scene and goes to the trampoline. I respond: 'I am not a girl'. John wrinkles his forehead and looks straight at me seriously and in a forceful tone states: 'You are not a boy. Only dads can come in'. I plead 'I can pretend to be your dad's wife'. He gazes at the ground for a few seconds, while James says in firm but quiet voice: 'No you can't'. John then looks up at me and explains apologetically: 'Dads have beer'. I ask: 'What do girls have?' James responds that 'Girls have drinks'. In a surprised tone I ask: 'What? 'Girls have beer' - Jonathan adds. 'No, girls have wine' - John corrects him. John sits back on his chair and spreads his leg and holds the arm of the chair with both hands with a straight face instructing me: 'Take a picture!' James stands up and goes to the wire rack on the ground with the plastic fish and crabs in a row. 'Is that a barbecue?' - I ask. James proceeds to remove the fish and crabs from the rack - 'The fish is ready' - he adds.

\section{Insert here Figure 1: Fishing boat and camping chairs}

The children delimit and configure an area in the garden of the preschool with selected objects, such as the boat, camping chairs, bottles, grass, plastic stands, wire rack and toy fish and crabs to produce the barbecue setting. The boys' T-shirts, all explicitly marketed for boys, portray giant monster trucks, bikes and cars. These objects and the circular arrangement of chairs next to the boat reproduce gatherings around the barbecue - a common way of socialising in Australian families. The socio-material and affective practices are performative here. They produce what Ingold and Kurttila (2000) term 'taskscapes' with shared conventions, surroundings and material installations, where a 'taskspace' is an "everyday space to which inhabitants have a practical and sensuous orientation that is shared but also continuously adapted" (in Edensor and Sumartojo 2018, 561). Acting the barbecue is heavily dependent on the configuration of objects, affective practices, such as slouching down, relaxing, enjoying each other's company, defending and supporting that create togetherness and a relaxed atmosphere in solidarity.

The space of the barbecue in which children perform does not pre-exist their performances. Space is actively present as children as enact socio-material practices and mobilize social norms and discourses (Gregson and Rose 2000). In this space, masculinity is actively performed and negotiated in 
relation to other identifications, such as girls or wives. The children actively engage in what Foucault (1982) describes as the dual process of subjectification - both as the subjects acting upon the existing conditions and being subjected to various discursive practices, in this case both the shared social life of the barbecue and the preschool. The children skilfully mobilize discourses, knowledge, socio-material and emotional practices, such as norms and barbecue rules, including drinking and excluding woman and regulating what can occur within this area, and what can be said and done and how one can feel and act out his emotions. Three boys subject themselves to dominant discourses operating in this space, and act and recognize themselves according to their experiences of barbecue. Interestingly, the boy who leaves the scene may not subscribe to these (or just wants to leave the game). The only girl present in the situation reacts with a smile to the gender exclusive statement but stays and remains silent. It is possible that the exclusionary discourse silences her ${ }^{2}$.

In an individual's experience the sense of who one is, depends on the weaving-together of multiple subject positions within discourses through various practices. As Wetherell and Edley (2014, p. 355) explain, for boys enacting masculinities, "[s] uch practices take many different forms and involve a wide range of activities, such as the disciplining of bodies to match currently ideal physiques, choices of clothes and fashion, leisure pursuits, gendered hierarchies in workplaces, and so on." The boys positioned themselves with drink bottles, chairs, choice of T-shirts, relaxed positions, facial expressions, tones of voice imitating male gatherings around the barbecue. John skilfully mixes this discourse with others present in this situation. John positions me possibly within two discourses, first, he draws on an exclusive masculine ideal, and second, on preschool discourses in relation to teachers' practices. In this latter he positions me as a teacher who does not interfere with children's game, which teachers in the preschool usually do, but only document the game by taking a photo. This discourse excludes me from their play, avoiding my inclusion as a wife. He may also position me as a foreigner not belonging to the scene due to her accent. Children frequently pointed out my accent and asked what language I was speaking claiming that it is not Australian.

With their affective practices, such as relaxation (relaxed mood and body positions), support for each other, and excluding (forceful tone of voice and expressionless face), the boys constitute a 'taskspace', perform some identifications, connect histories, (re)create social orders and perform institutional practices in relation to an old-fashioned and highly stereotypical national trope of barbecue and camaraderie. Affect activates the children's corporeal histories through connecting different bodies, objects and place and renders them relevant for this specific situation (Militz 2017). In this way, affect, discourse, history and social life are all tied together and affect is linked to convention and assumed

\footnotetext{
${ }^{2}$ It is also possible that she does not understand the barbecue as an exclusively male domain. She may also want to enact the masculine discourse.
} 
normal practice. At the barbecue, "so the myths go, Australians manifest the informality, classlessness, and love of the natural that typifies 'Australia"' (Bradford 1995, 112). Barbecue symbolizes a stereotypical relaxed Australian lifestyle in outdoor spaces generating an interpersonal quality of shared social life with an inherently egalitarian quality. Drinks and food cement the bonds between males, termed 'mateship' in Australia, a longstanding but transforming Anglo-Australian nationalist gravity (Kapferer 1988).

Mateship is a bush-derived 'Australian Legend' originating in the settler colonialist period of British imperialism and glorified in sports and war (Pease 2001). During settler colonialism, and due to the harshness of the bush and the often violent relations with Indigenous people, the behavioral code of mateship was born in which a man would do anything to protect and support a mate in the absence of females who were kept safe at a safe distance (Pease 2001). By the late nineteenth-century, radical and labour intellectuals transformed this bush ideal into a politicized mateship essential to the making of a 'positive' working-class Australian identity (Pease 2001; Dyrenfurth 2007). In a more general trope, mateship represents visions of solidarity, collectivism and mutuality with a strong emotional charge. Being accepted as an "Anglo-Celtic mate" meant that one belonged to a category of "extra-class whiteness" (Hage 1998, 199). At the end of the twentieth century these ideals were still an important part of Australian national identity (Pease 2001), despite the actual diversity and Australian governmental agencies advancing a more progressive and inclusive imaginary of nation (Turner 1994). One of the paradigmatic features of the 'Australian' barbecue trope is the marked gender separation (Redmond 2007). At the barbecue, men share cooking and drinking together, usually excluding females. Men gather around the barbecue, while women often look after children and/or prepare salads or mix drinks elsewhere. Expressed in the colloquialism: 'men, meat and metal', the shared social life of males around the barbecue invokes a "sacrificial male homosociality" (Redmond 2007, 338).

In the first event, national discourses were mobilized and enacted by the teacher as she read the book and affectively performed its characters drawing children into the story and inviting their emotional identification with the Australian characters. In the second event, particular masculine national identifications were re/produced by the children with the emotional practices of mateship. Histories and material objects were actively recruited in both performances referencing highly specific forms of clichéd nationalism: iconic foods and places and white working-class Australian masculinity. Through children's imaginary participation in consuming food and travelling in Australia and their performance of stereotypical Australian lifestyle, the fictional nation appeared real. In the realization of nation affective practices did not only play crucial roles but also encouraged children to understand themselves in relation to these discourses. The affective practices of the teacher performing nation as she read the book and the affective practices of the children as they subjected themselves to the national trope of the barbecue created national spaces within the preschool in which children could understand themselves as national 
subjects and learn to and feel for the nation.

\section{Discussion}

National stereotypes have "been a problem in education for a long time, and it is not unusual even today to find stereotyping in textbooks that supports inclusion and exclusion between national groups and therefore favors nationalism in education" (Paasi 1999, 14). However, practices that maintain and remake the imaginary nation in the everyday life of preschools are rarely explored in research. Sociomaterial and emotional practices that maintain nationalist tropes, as I have shown, fit seamlessly into regular pedagogy and practices, thus they are hard to recognize. This is the very reason why they need to be paid critical attention to and challenged. The emotional practice of nation I have made visible and the quintessentially Australian books and the 'taskscape' I have analysed show the continued use and investments made in obsolete representations, which is highly problematic. As Turner (1994) explains, since the 1990s Australia has been characterized by notions of plurality and hybridity. Cultural difference is seen as constitutive of Australian national identity rather than a deviation from an Anglocentric and normative identity that Possum Magic conjures up. In Edensor and Sumartojo's (2018) study, participants from inner-city Melbourne richly demonstrate a unanimous focus on the multicultural dimensions of their experience of the national. In my study located in a more rural and less multicultural setting, everyday nation is constituted from different experiences. For this reason, letting children to play freely with these tropes and stereotypes might (re)produce ossified power relations, national ideologies and exclusions. Power relations and unwanted and discriminatory stereotypes in free play have been critiqued in research (see Grieshaber and McArdle 2010), yet outdated and exclusionary nationalist tropes are rarely part of these critiques. Perhaps this is so because so far no attention has been paid to make visible in research the mundane mechanisms that enrol these tropes in to everyday practices.

Critical curriculum studies level criticism at textbooks and children's literature on the grounds of socialising children into unwanted, unproductive and dangerous ideologies that reinstate power hierarchies and exclusions. Nonetheless it seems that national ideologies if disguised in the form of cute Australian animals and their consumption of quintessentially 'Australian' food, or as free play, can pass under the radar of the most vigilant pedagogues, such as the teacher in the preschool, who is passionate about social justice. Making visible everyday nationalism and its affective dimensions can reveal the dynamic, multiple and contextual ways in which children are invited, inspired and seduced to nation and perform and feel nation in shared social life. However, outdated, colonial, racist, classist and genderist national tropes form part of everyday life in children's institutions despite progress to promote more inclusionary nationalism. I showed how affective practices contribute to or help sustain their uncritical uptake. This kind of nationalism, as Billig (1995) has shown, is banal but not benign. Having a strong 
and efficient ideological pull, they are "able to pass for 'patriotism', a familiar beast" (Throssel 2015, 17). These tropes contribute to the maintenance of exclusionary discourses that children can mobilize for their identifications or remain unaffected by them, or actively reject or challenge those. While enabling and facilitating these engagements is part of everyday pedagogies, they could be also used to encourage children's engagement with inclusive national ideals and thus perform more conscious and inclusive pedagogies of nation (Millei 2019).

\section{References}

Adomat, D. S. 2010. "Dramatic Interpretations: Performative Responses of Young Children to Picturebook Read-Alouds". Children's Literature in Education, 41(3): 207-221.

Ahmed, S. 2014. The cultural politics of emotion. ( $2^{\text {nd }}$ Ed.) Edinburgh: Edinburgh University Press

Anderson B. 2009. Affective atmospheres. Emotion, Space and Society 2: 77-81

Antonsich, M. and Skey, M. 2017. Affective nationalism: Issues of power, agency and method. Progress in Human Geography, 41(6): 843-845

Beneï, V. 2008. Schooling Passions: Nation, History, and Language in Contemporary Western India. Stanford, CA: Stanford University Press.

Billig, M. 1995. Banal Nationalism. London: SAGE.

Brubaker, R. 2006. Nationalist politics and everyday ethnicity in a Transylvanian town. Princeton: Princeton University Press.

Bradford, C. 1995. "Exporting Australia: National Identity and Australian Picture Books" Children's Literature Association Quarterly, 20(3): 111-115.

Closs Stephens, A. 2016. "The affective atmospheres of nationalism”. Cultural Geographies 23(2): 181-198. Daniel, C. 2006. Voracious Children: Who Eats Whom in Children's Literature. New York: Routledge.

Edensor, T. and Sumartojo, S. 2018. Geographies of everyday nationhood: experiencing multiculturalism in Melbourne. Nations and Nationalism, 24 (3): 553-578.

Fox, J. E. and Miller-Iddriss C. 2008. Everyday nationhood. Ethnicities, 8: 536-563.

Van Ginderachter, M. 2018. Introduction: Everyday nationalism's evidence problem. Nations and Nationalism, 24(3): 546-623.

Fox, M. 1987. Possum Magic. Adelaide: Omnibus.

Goodwin, M. H. 2006. The Hidden Life of Girls: Games of Stance, Status and Exclusion. Malden, MA: Blackwell. Gregson, N. and Rose, G. 2000. Taking Butler elsewhere: Performativities, spatialities and Subjectivities. Environment and Planning D: Society and Space, 18: 433-452

Grieshaber, S. and McArdle, F. 2010. The Trouble with Play. Maidenhead, England: Open University Press Hage, G. 1998. White Nation: Fantasies of Supremacy in a Multicultural Society. Sydney: Pluto Press.

Häkli, J. 2015. The border in the pocket: Passport as a boundary object. 85-99. In Amilhat-Szary, A. L. and Giruat, F. (Eds) Borderities and the politics of contemporary mobile borders. Basingstoke: Palgrave Macmillan. Kapferer, B. 1988. Legends of People, Myths of State: Violence, Intolerance, and Political Culture in Sri Lanka and Australia. Washington, DC: Smithsonian Institution Press.

Lappalainen, S. 2006. "Liberal multiculturalism and national pedagogy in a Finnish preschool context: inclusion or nation-making?” Pedagogy, Culture and Society, 14(1): 99-112

Mavroudi, E. and Holt, L. 2015 (Re)constructing nationalisms in schools in the context of diverse globalized societies. In Governing through diversity: Migration societies in post-multiculturalist times. Edited by T. Matejskova and M. Antonsich, 181-201 Basingstoke and New York: Palgrave MacMillan

MacNaughton, G. 2001. Back to the future - young children constructing and reconstructing 'White' Australia. Early childhood education for a democratic society. From Conference Proceedings. 
Wellington: NZCER Distribution Services (37-52).

Merriman, P. and Jones, R. 2017. "Nations, materialities and affects". Progress in Human Geography. 41(5): 600-617.

Millei, Z. (2019) At the temporal edge of the nation: Young children and everyday nationalism. Childhood, 26(1) 83-97.

Millei, Z. \& Imre, R. (Eds) (2015) Childhood and Nation: Interdisciplinary Engagements. New York: Palgrave MacMillan.

Paasi, A. 1999. "Nationalizing Everyday Life: Individual and Collective Identities as Practice and Discourse". Geography Research Forum, 19: 4-21

Pink, S. 2009. Doing Sensory Ethnography. London: Sage

Procter, L. 2013. Exploring the role of emotional reflexivity in research with children. Emotion, Space and Society, 9: 80-88.

Redmond, A. 2007. "Surfies versus westies: kinship, mateship and sexuality in the cronulla riot". The Australian Journal of Anthropology, 18(3): 336-350

Turner, G. 1994. Making It National- Nationalism and Australian Popular Culture. St. Leonards: Allen and Unwin.

Silova, I., Mead Yaqub M.A., Mun O. and Palandjian G. (2014). Pedagogies of space: (Re)imagining nation and childhood in post-Soviet states. Global Studies of Childhood, 4(3): 195-209.

Sipe, L. R. 2008. Storytime: Young Children's Literary Understanding in the Classroom. New York: Teachers College Press.

Stephens, S. 1995. Children and the Politics of culture. Princeton, NJ: Princeton University Press

Throssell K. 2015. Child and Nation: A Study of Political Socialisation and Banal Nationalism in France and England. New York: Peter Lang S.A.

Zembylas, Z. 2009. Affect, citizenship, politics: implications for education. Pedagogy, Culture and Society, 17(3): 369-383.

Wetherell, M. 2012. Affect and Emotion: A New Social Science Understanding. London: Sage.

Wetherell, M. 2015. Trends in the Turn to Affect: A Social Psychological Critique. Body and Society, 21(2): 139-166.

Wetherell, M. and Edley, N. 2014. A Discursive Psychological Framework for Analyzing Men and Masculinities. Psychology of Men and Masculinity, 15(4): 355-364.

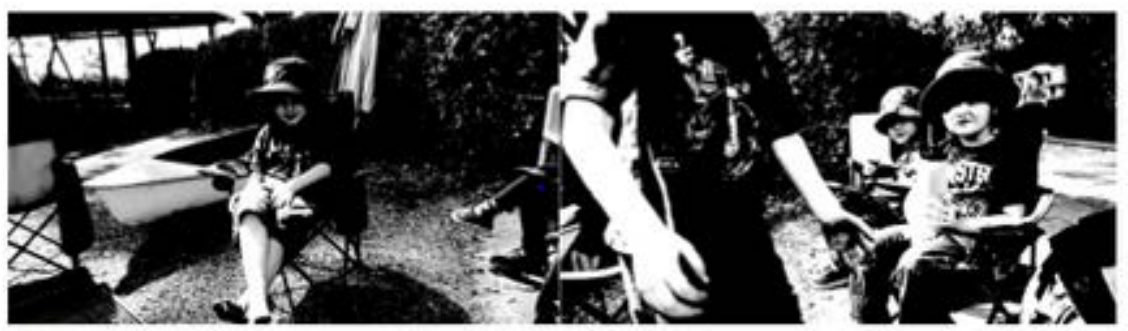

Figure 1: Fishing boat and camping chairs 